\title{
Assessment of Complicated Anterior Abdominal Wall Hernia by Ultrasonography and Colour Doppler
}

\author{
Yara Ibrahim Abdel Hamid*, Enas Mohamed Khattab, Ahmed Abdel Azim Isamail, Sameh Saber Baioumy \\ Department of Radiodiagnosis, Faculty of Medicine, Zagazig University, Egypt \\ *Corresponding author: Yara I. Abdel Hamid, Mobile: (+20) 01158925343, Email: dryara100@yahoo.com
}

\begin{abstract}
Background: A hernia is defined as a protrusion from a structure through the normally tissues containing it, either a focal or diffuse defects in the tissues with many types including: inguinal, femoral, umbilical and paraumbilical, epigastric and incisional hernias. Objective: This study aimed to evaluate anterior abdominal wall hernia using ultrasound and color Doppler. Patients and methods: An interventions study included (48) patients who were referred from the Surgery Department, Zagazig University Hospitals for sonographic evaluation of the abdominal wall and the abdomen when their clinical presentations were suggestive of abdominal wall hernia obstruction, either progressed or not progressed to bowl obstruction, when their physical examinations were inconclusive or when surgeons believed it was important to determine the contents of a suspected hernia preoperatively. Results: The mean age of the studied patients was $47.5 \pm 21.88$ years old, with a range from 3 months to 66 years old, less than $1 / 2$ of the studied patients were males $(41.7 \%$ ) and $58.3 \%$ were females. About $100 \%$ of the studied hernias were irreducible containing omentum, while hernias were containing bowel in $95.8 \%$ of cases, $41.7 \%$ of cases contained free fluid in hernia sac, $47.8 \%$ of the studied patients had absent bowel peristalsis. Comparing the ultrasound finding with the operative data revealed that ultrasound had $100 \%$ sensitivity, while accuracy in diagnosis of peristalsis, bowel irreducibility, bowel thickness ranged from $93.4 \%$ to $98.8 \%$. Conclusion: High-resolution ultrasonography (US) is an efficient tool for detecting the presence of abdominal wall hernias and accurately detecting the content, and the possible associated complications.
\end{abstract}

Keywords: Abdominal hernia, Doppler, Sonographic evaluation, Ultrasonography

\section{INTRODUCTION}

A hernia is the protrusion of a structure through the tissues normally containing it, either through a focal defect in the tissue or stretching of the tissue (1). Predisposing factors for hernia are developmental anomalies, chronic cough, obesity, ascites, previous surgery, trauma, pregnancy, impaired wound healing, and aging ${ }^{(2)}$. The most common hernias are the inguinal hernias. Inguinal hernias are further divided into the more common indirect inguinal hernia. There are cases in which the hernia may contain both direct and indirect hernia simultaneously; pantaloon hernia ${ }^{(3)}$.

Femoral hernias is a rare hernia that is more common in women, possibly because of pregnancy ${ }^{(4)}$. Umbilical and paraumbilical hernias involve protrusion of intra-abdominal contents through a weakness at the site of passage of the umbilical cord through the abdominal wall ${ }^{(5)}$. Epigastric hernia occurs in the midline above the umbilicus till the xiphisternum. Diastasis of the rectus abdominis muscle often predisposes to epigastric hernias and fatty hernia of the linea alba ${ }^{(6)}$.

Incisional hernia is an important type of hernia that is located at the scar from previous surgery as a delayed complication of abdominal surgery ${ }^{(4)}$.

The most common complications of abdominal wall hernias are bowel obstruction secondary to the hernia, incarceration, and strangulation. These complications can often be detected at clinical evaluation. Presenting symptoms may include abdominal pain, vomiting, and distention. Physical examination may reveal a firm, tender abdominal wall mass ${ }^{(7)}$.
Imaging studies are required when the clinical manifestation is misleading or inconclusive or preoperative assessment of the hernia. Moreover, early diagnosis of hernia complications is feasible using ultrasound examination, potentially improving patient outcome by preserving bowel viability. Ultrasound give information on the herniated organs, the presence of peritoneal fluid, the presence or absence of color Doppler signals in the hernial contents and the presence or absence of peristalsis in the herniated bowel loop may be detected ${ }^{(\mathbf{1})}$.

Therefore, the present study aimed to evaluate of anterior abdominal wall hernia using ultrasound and color Doppler.

\section{PATIENTS AND METHODS}

An interventions study included (48) patients of 28 females and 20 males, with an age range from 3 month to 66 years old. These cases were referred from the Surgery Department, Zagazig University Hospitals for sonographic evaluation of the abdominal wall and the abdomen when their clinical presentations were suggestive of abdominal wall hernia obstruction, either progressed or not progressed to bowl obstruction, when their physical examinations were inconclusive or when surgeons believed it was important to determine the contents of a suspected hernia preoperatively.

This study included a patient clinically presented with acute inguinal lump with suspected obstructed abdominal wall inguinal hernia and some cases were referred for sonography due to vomiting and abdominal pain of unobvious cause. This work was

This article is an open access article distributed under the terms and conditions of the Creative 
performed at Ultrasound Unite of the Radiodiagnosis Department at Zagazig University Hospitals.

\section{Inclusion and exclusion criteria:}

Patient with anterior abdominal wall hernia with any age and sex. While, non-cooperative patients and infected skin at site of hernia were excluded from this study.

All patients were subjected to complete history taking and full clinical examination of the abdominal wall was performed for all patients by the referring physicians and radiological examination including ultrasound and Doppler for all cases. X-Ray were performed for intestinal obstruction if needed.

\section{Imaging protocol and Technique:}

Ultrasound equipment included an LOGIC V5 unit with 2- to 4-MHz curved array and 7- to $11-\mathrm{MHz}$ linear array transducers. Color Doppler sonography was performed using the previously mentioned linear array transducer. Sonography was performed on patients in supine position, and the Valsalva's or coughing and slight compression maneuvers were almost always performed during the examination to confirm or exclude the irreducibility of the hernia. To evaluate the peristalsis of herniated bowel loops, the transducer was held motionless over the hernia for approximately 2 minutes. Color-Doppler analysis was done to increases diagnostic power of the method detecting circulatory alterations. At least four images on several planes were obtained of each hernia and documented on film. Color Doppler settings were adjusted for maximal blood flow sensitivity. These settings included a wall filter of $50 \mathrm{~Hz}$, a pulse repetition frequency of 2-20, maximum power, and the highest possible gain at a usable ratio of signal to background noise.

\section{Ethical consent:}

An approval of the study was obtained from Zagazig University Academic and Ethical Committee. Every patient signed an informed written consent for acceptance of sharing in the study. This work has been carried out in accordance with The Code of Ethics of the World Medical Association (Declaration of Helsinki) for studies involving humans.

\section{Statistical analysis}

The collected data were analyzed by computer using Statistical Package for the Social Sciences version 24 (SPSS). Continuous quantitative variables, e.g. age were expressed as the mean \pm SD (Standard deviation) and median (range), and categorical qualitative variables were expressed as absolute frequencies (number) and relative frequencies (percentage).

\section{RESULTS}

Demographic data and US findings of the studied patients are shown in table 1 .

Table (1): Demographic data and ultrasound findings of the studied patients $(n=48)$

\begin{tabular}{|c|c|c|}
\hline \multirow{2}{*}{ Demographic data } & \multicolumn{2}{|c|}{ Studied patients $(\mathrm{N}=48)$} \\
\hline & \begin{tabular}{|l|l|} 
No. & \\
\end{tabular} & $\%$ \\
\hline \multicolumn{3}{|l|}{ Sex } \\
\hline - Male & 20 & 41.7 \\
\hline - Female & 28 & $\begin{array}{ll}71.1 \\
58.3\end{array}$ \\
\hline \multicolumn{3}{|l|}{ Age (years) } \\
\hline - Mean \pm SD & \multicolumn{2}{|c|}{$47.5 \pm 21.88$} \\
\hline - Median (Range) & \multicolumn{2}{|c|}{58.5 (3 months -66 years) } \\
\hline Ultrasound findings & \multicolumn{2}{|c|}{ Studied patients $(\mathrm{N}=48)$} \\
\hline \multicolumn{3}{|l|}{ Content } \\
\hline - Bowel & 46 & 95.8 \\
\hline - Omentum & 48 & 100.0 \\
\hline - Fluid in sac & 20 & 41.7 \\
\hline \multicolumn{3}{|l|}{ Bowel peristalsis $(n=46)$} \\
\hline - Absent & 22 & 47.8 \\
\hline - Normal & 24 & 52.2 \\
\hline \multicolumn{3}{|l|}{ Reducibility } \\
\hline - Irreducible & 48 & 100.0 \\
\hline - Reducible & 0 & 0.0 \\
\hline \multicolumn{3}{|l|}{ Defect size $(\mathbf{C m})$} \\
\hline - Mean \pm SD & \multicolumn{2}{|c|}{$1.96 \pm 0.96$} \\
\hline - Median & \multicolumn{2}{|c|}{1.9} \\
\hline \multicolumn{3}{|l|}{ Wall thickness (mm) } \\
\hline - Mean \pm SD & \multicolumn{2}{|c|}{$3.2 \pm 0.77$} \\
\hline - Median & \multicolumn{2}{|l|}{3.2} \\
\hline Doppler U/S finding & \multicolumn{2}{|c|}{ Studied patients $(\mathrm{N}=48)$} \\
\hline \multicolumn{3}{|c|}{ Blood flow at hernia contents } \\
\hline - Absent & \multicolumn{2}{|l|}{13} \\
\hline - Present & 35 & 72.9 \\
\hline
\end{tabular}

As regard complications most of the studied cases had irreducible hernia (Table 2).

Table (2): Percent of complication among the studied cases

\begin{tabular}{|l|l|l|}
\hline \multirow{2}{*}{ Complication } & \multicolumn{2}{|l|}{ Studied patients $(\mathbf{N}=\mathbf{4 8})$} \\
\cline { 2 - 3 } & No. & \% \\
\hline - Irreducible hernia & 46 & 95.8 \\
\hline - Bowel Obstruction & 14 & 29.2 \\
\hline - Recurrent hernia & 3 & 6.3 \\
\hline - Strangulated Hernia & 13 & 27.1 \\
\hline
\end{tabular}

Among the studied group, 13 patients (27\%) had associated bowel ischemia (Table 3).

Table (3): Percent of bowel ischemia among the studied cases

\begin{tabular}{|c|l|l|l|l|l|}
\hline \multicolumn{2}{|c|}{} & \multicolumn{2}{|c|}{$\begin{array}{c}\text { Ischemic } \\
\text { bowel (n=13) }\end{array}$} & $\begin{array}{l}\text { Non-ischemic } \\
\text { bowel (n=35) }\end{array}$ \\
\cline { 3 - 7 } \multicolumn{2}{|c|}{} & $\mathbf{N}$ & $\mathbf{\%}$ & $\mathbf{N}$ & $\mathbf{\%}$ \\
\hline \multirow{4}{*}{ Site } & Epigastric & 0 & 0.0 & 3 & 8.6 \\
\cline { 2 - 6 } & Incisional & 5 & 38.5 & 3 & 8.6 \\
\cline { 2 - 6 } & Inguinal & 0 & 0.0 & 17 & 48.6 \\
\cline { 2 - 6 } & Paraumbilical & 0 & 0.0 & 5 & 14.3 \\
\cline { 2 - 6 } & Femoral & 2 & 15.4 & 3 & 8.6 \\
\cline { 2 - 6 } & Umbilical & 6 & 46.1 & 4 & 11.4 \\
\hline
\end{tabular}

Reduction of viable loops and herniorrhaphy were done in $45.8 \%$ of patients, reduction of viable loops and hernioplasty in $22.9 \%$ of cases, while resection and primary anastomosis were done in $14.6 \%$ of cases (Table 4). 
Table (4): Operation done among the studied patients

\begin{tabular}{|l|l|l|}
\hline \multirow{2}{*}{ Operation } & $\begin{array}{l}\text { Studied } \\
(\mathbf{N}=\mathbf{4 8})\end{array}$ & patients \\
\cline { 2 - 3 } & $\mathbf{N o .}$ & $\mathbf{\%}$ \\
\hline - Exploration the bowel loops then colostomy & 4 & 8.3 \\
\hline - Reduction of viable loops and hernioplasty & 11 & 22.9 \\
\hline - Reduction of viable loops and herniorrhaphy & 22 & 45.8 \\
\hline - Resection and primary anastomosis & 7 & 14.6 \\
\hline - Hot fomentation then reduction & 2 & 4.2 \\
\hline - Omentectomy and herniorrhaphy & 2 & 4.2 \\
\hline
\end{tabular}

Comparing the ultrasound findings with the operative data revealed that ultrasound had $100 \%$ sensitivity, while accuracy in diagnosis of peristalsis, bowel irreducibility, bowel thickness ranged from $93.4 \%$ to $98.8 \%$. Also Doppler accuracy was 100\% (Table 5).

Table (5): Accuracy of US related to operative findings among the studied patient

\begin{tabular}{|c|c|c|c|c|c|}
\hline \multirow{2}{*}{ US } & \multicolumn{2}{|c|}{ Operative finding } & \multirow{2}{*}{ Sensitivity } & \multirow{2}{*}{ PVP } & \multirow{2}{*}{$\begin{array}{l}\text { Accuracy } \\
95 \% \text { (C.I) }\end{array}$} \\
\hline & Confirmed & Un-confirmed & & & \\
\hline Bowel peristalsis $(n=46)$ & $44(95.7 \%)$ & $2(4.2 \%)$ & $100 \%$ & $95.6 \%$ & $\begin{array}{l}95.7 \% \\
(86.4-98.8)\end{array}$ \\
\hline Reducibility & $46(95.8 \%)$ & $2(4.2 \%)$ & $100 \%$ & $95.8 \%$ & $\begin{array}{l}95.8 \% \\
(86.0-98.8)\end{array}$ \\
\hline Bowel thickness $(n=46)$ & $43(93.5 \%)$ & $3(6.5 \%)$ & $100 \%$ & $93.4 \%$ & $\begin{array}{l}93.4 \% \\
(82.5-97.7)\end{array}$ \\
\hline Doppler & $4(100 \%)$ & $0(0.0 \%)$ & $100 \%$ & $100 \%$ & $\begin{array}{l}100.0 \% \\
(92.5-100)\end{array}$ \\
\hline
\end{tabular}

\section{CASE (1):}

45 years old, male patient, known to have an umbilical hernia, presented with irreducible painful umbilical lump and abdominal pain and vomiting (Figure 1). Diagnosis was strangulated umbilical hernia associated with bowel obstruction and the patient underwent exploration, resection and primary anastomosis.

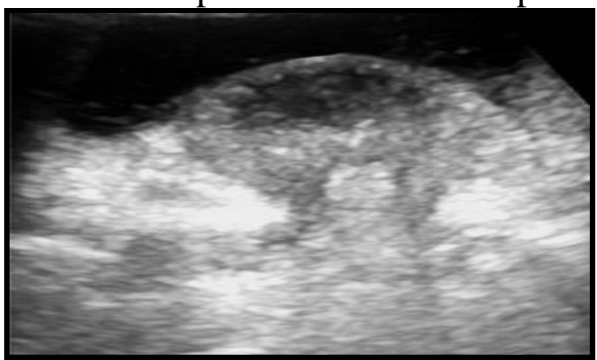

(A)

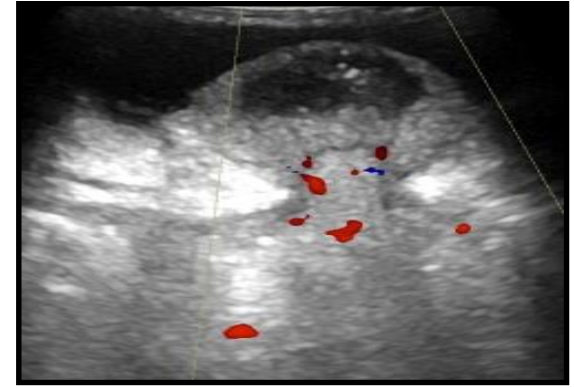

(C)

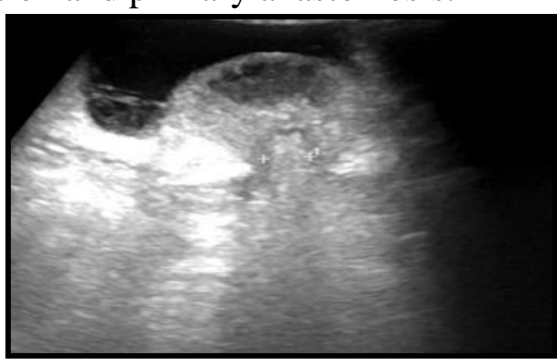

(B)

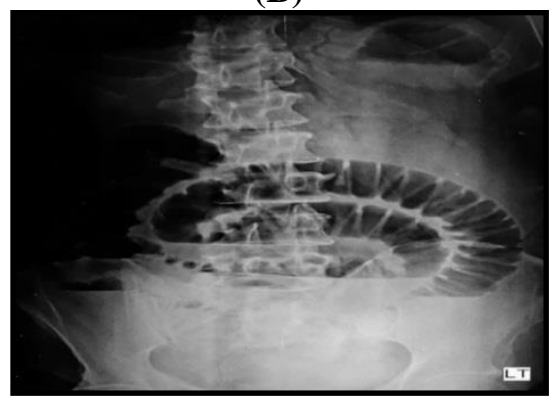

(D)

Fig. (1): Sonography and X-ray evaluation of case 1

Ultrasound revealed (A) irreducible thick walled bowl loops $(4 \mathrm{~mm})$, with free fluid within the hernial sac, (B) defect measure $0.95 \mathrm{~cm}$ (C) absent flow within the bowl wall. (D) $X$ ray showed marked dilated bowel loops with multiple air fluid level confirming intestinal obstruction. 


\section{DISCUSSION}

Our study included 48 patients dedicated to the evaluation of anterior abdominal wall hernia complications diagnosed by sonography and confirmed by operative diagnosis.

Regarding demographic data, patient ages ranged between 3 months to 66 years with a peak incidence of presentation in the six followed by the fifth decade. This could be explained by the age related deterioration and weakness of the abdominal boundaries. The mean age \pm SD in our study was $47.5 \pm$ 21.88 years similar to a recent study by Jayaram $\boldsymbol{e t}$ al. ${ }^{(I)}$, who reported a mean age of 53.4 years (range 16-97), Young et $\boldsymbol{a l} .{ }^{\left({ }^{(8)}\right.}$, reported mean age 47 years old. The number of females suffering from anterior abdominal wall hernia was more than males (28 versus 20 ). This could be explained by the higher incidence of surgeries in females, e.g., Cesarean section which is the most commonly performed surgical procedure in the world literature ${ }^{(9)}$. Devareddy et al. ${ }^{(10)}$ and Baz et al. ${ }^{(11)}$ reported a similar female predominance, but Young $\boldsymbol{e t}$ al. ${ }^{(8)}$ reported a majority of males patients in their study, may be due to large sample size and different study design.

Regarding clinical data, the main complaint was lump, $31.3 \%$ complained of lump plus vomiting, $20.8 \%$ complained of lump plus constipation, $22.9 \%$ complained of lump and abdominal pain. These results agreed with result of Baz et al. ${ }^{(11)}$ and Lee et al. ${ }^{(12)}$ who reported that the dominant presenting symptom was mass.

Regarding the type of a hernia, the current study showed that the predominant type of hernia was the inguinal hernia (35.4\%) followed by the ventral hernia (31.2\%), then the incisional hernia (16.7\%). This was discordant with the results reported by Baz et al. ${ }^{(11)}$ who had documented that the ventral hernia was the frequent one $(48.3 \%)$ followed by the inguinal type (38.7\%). Devareddy et al. ${ }^{(10)}$ reported that incisional hernia (44\%) was the frequent one followed by ventral hernias $(14 \%)$ and this could be explained by the small sample size in both studies.

Our data suggest that the absence of blood flow in the contents of a hernia is the most important sign of strangulation because almost all strangulated hernias in our series $(27 \%)$ had no detectable blood flow on color Doppler sonography. The patients in whom color Doppler sonography did not detect blood flow in the incarcerated bowel loop were patients with incarcerated hernia and bowel necrosis confirmed by surgery. This agreed with a study by Devareddy et al. ${ }^{(10)}$ who found that color Doppler sonography was effective in differentiation between strangulated and nonstrangulated hernias and with Liang et al. ${ }^{(13)}$ who found an added value of color Doppler in evaluating the vascular status of hernias.

Our study revealed that by early diagnosis serious complications of incarceration can be prevented, also reduce the risk of emergency herniorrhaphy. The viability was important in choosing the treatment plan for hernia. Bowel viability was the main determinant as it affect the safety and the effectiveness of manual or surgical reduction. Manual reduction of the incarcerated hernia may convert the treatment plan from emergency surgery to an elective operation thereby decrease the mortality risk. We observed this scenario in two patients in our study. When color Doppler US showed a visible flow, manual reduction was attempted but if it was unsuccessful surgical reduction and repair were done. When color Doppler showed absent flow which means ischemia and necrosis, surgical bowel resection was done immediately to preserve viable bowel. Our findings match those of Young et al. ${ }^{(8)}$ who stated that US is useful to check for hernias when planning abdominal hernia surgical procedures, particularly large or multiple recurrent hernias.

We observed scenario in two patients in our study. Almost all patients with an incarcerated hernia containing bowel can be expected to have complete bowel obstruction. For the absence of this sign in a relatively high percentage of patients, that may be due to incomplete incarceration, some chyme passed through, the time from the onset of incarceration to diagnostic imaging was too short to develop dilatation of bowel loops in the abdomen. This agreed with a study by Rettenbacher et al. ${ }^{(14)}$ who found that intestinal obstruction may be an indirect sign for hernias incarceration and vomit may be the only presenting symptom.

\section{CONCLUSION}

High-resolution ultrasonography (US) is an efficient tool for detecting the presence of abdominal wall hernias and accurately detecting the content, and the possible associated complications.

\section{Financial support and sponsorship: Nil.}

\section{Conflict of Interest: Nil.}

\section{REFERENCES}

1. Jayaram P, Pereira F, Barrett J (2018): Evaluation of dynamic ultrasound scanning in the diagnosis of equivocal ventral hernias with surgical comparison. The British Journal of Radiology, 91: 1088-1093.

2. Murphy K, O'Connor O, Maher M (2014): Adult abdominal hernias. American Journal of Roentgenology, 202(6): 506-511.

3. Alonso F, Graham R, Rustagi T et al. (2017): The subcostal nerve during lateral approaches to the lumbar spine: an anatomical study with relevance for injury avoidance and postoperative complications such as abdominal wall hernia. World Neurosurgery, 104: 669673.

4. Cherla D, Bernardi K, Blair $\mathrm{K}$ et al. (2019): Importance of the physical exam: double-blind randomized controlled trial of radiologic interpretation of ventral hernias after selective clinical information. Hernia, 23(5):987-994. 
5. Lassandro F, Iasiello F, Pizza $\mathrm{N}$ et al. (2011): Abdominal hernias: radiological features. World Journal of Gastrointestinal Endoscopy, 3(6): 110-115.

6. Sancho M, Pascoal A, Mota P et al. (2015): Abdominal exercises affect inter-rectus distance in postpartum women: a two-dimensional ultrasound study. Physiotherapy, 101(3): 286-291.

7. Aguirre D, Santosa A, Casola G et al. (2005): Abdominal wall hernias: imaging features, complications, and diagnostic pitfalls at multi-detector row CT. Radiographics, 25(6) 1501-1520.

8. Young J, Gilbert A, Graham M (2007): The use of ultrasound in the diagnosis of abdominal wall hernias. Hernia, 11(4): 347-351.

9. Zafar H, Levine M, Rubesin S et al. (2006): Anterior abdominal wall hernias: findings in barium studies. Radiographics, 26:691-699.

10. Devareddy M, Devakar S, Chetan M (2016): Evaluation the sonographic appearance of spectrum of anterior abdominal wall lesions and to compare the sonological features with pathological and operative diagnosis: A cross-sectional study. International Journal of Scientific Study, 4(7): 112-119.

11. Baz A, El-Azizi H, Mohamed M et al. (2019): Role of high-resolution ultrasound in the assessment of abdominal wall masses and mass-like lesions. Egyptian Journal of Radiology and Nuclear Medicine, 50(1): 3336.

12. Lee R, Cho C, Tong C et al. (2013): Ultrasound of the abdominal wall and groin. Canadian Association of Radiologists Journal, 64(4): 295-305.

13. Liang D, Jacobson J, Morag et al. (2006): Sonography of inguinal region hernias. American Journal of Roentgenology, 187(1): 185-190.

14. Rettenbacher T, Hollerweger A, Macheiner $\mathbf{P}$ et al. (2001): Abdominal wall hernias: cross-sectional imaging signs of incarceration determined with sonography. American Journal of Roentgenology, 177(5): 1061-1066. 